\title{
Erratum to: A longitudinal epidemiological comparison of suicide and other causes of death in Italian children and adolescents
}

\author{
Maurizio Pompili • Monica Vichi • Diego De Leo • \\ Cynthia Pfeffer $\cdot$ Paolo Girardi
}

Published online: 17 February 2013

(C) Springer-Verlag Berlin Heidelberg 2013

Erratum to: Eur Child Adolesc Psychiatry (2012)

\section{1:111-121}

DOI 10.1007/s00787-011-0238-5

In the article mentioned above, some passages within the introduction originate from the article: Lahti A, Räsänen P, Riala K, Keränen S, Hakko H (2011) Youth suicide trends in Finland, 1969-2008. J Child Psychol Psychiatry 52(9): 984-991. Corresponding author: Lahti A: lahtia@mail. student.oulu.fi.

Although the article has been cited, the reference is missing at the corresponding passages in the introduction.

The online version of the original article can be found under doi:10.1007/s00787-011-0238-5.

\footnotetext{
M. Pompili · P. Girardi

Department of Neurosciences, Mental Health and Sensory Functions, Suicide Prevention Center, Sant'Andrea Hospital,

Sapienza University of Rome, Rome, Italy

M. Pompili

McLean Hospital, Harvard Medical School, Boston, USA

M. Pompili ( $\square)$

Department of Psychiatry, Sant'Andrea Hospital, Sapienza University of Rome, Via di Grottarossa 1035, 00189 Rome, Italy e-mail: maurizio.pompili@uniroma1.it; mpompili@mclean.harvard.edu

M. Vichi $(\bowtie)$

National Centre for Epidemiology, Surveillance and Health

Promotion (CNESPS), National Institute of Health (ISS),

Via Giano della Bella 34, 00161 Rome, Italy

e-mail: vichi@iss.it
}

\author{
D. De Leo \\ Australian Institute for Suicide Research and Prevention, \\ WHO Collaborating Centre for Research and Training in Suicide \\ Prevention, Griffith University, Brisbane, Australia \\ C. Pfeffer \\ Department of Psychiatry, Weill Medical College of Cornell \\ University, White Plains 10605, USA
}

